\title{
Strong convergence theorems for the split variational inclusion problem in Hilbert spaces
}

\section{Chih-Sheng Chuang*}

\section{"Correspondence:}

cschuang1977@gmail.com

Department of Applied

Mathematics, National Sun Yat-sen

University, Kaohsiung, Taiwan

\begin{abstract}
In this paper, we first consider a split variational inclusion problem and give several strong convergence theorems in Hilbert spaces, like the Halpern-Mann type iteration method and the regularized iteration method. As applications, we consider the algorithms for a split feasibility problem and a split optimization problem and give strong convergence theorems for these problems in Hilbert spaces. Our results for the split feasibility problem improve the related results in the literature.
\end{abstract}

MSC: 47H10; 49J40; 54H 25

Keywords: zero point; split feasibility problem; resolvent mapping; optimization problem

\section{Introduction}

In 1994, the split feasibility problem in finite dimensional Hilbert spaces was first introduced by Censor and Elfving [1] for modeling inverse problems which arise from medical image reconstruction. Since then, the split feasibility problem has received much attention due to its applications in signal processing, image reconstruction, approximation theory, control theory, biomedical engineering, communications, and geophysics. For examples, one can refer to [1-5] and related literature.

We know that the split feasibility problem can be formulated as the following problem:

(SFP) Find $\bar{x} \in H_{1}$ such that $\bar{x} \in C$ and $A \bar{x} \in Q$,

where $C$ and $Q$ are nonempty closed convex subsets of Hilbert spaces $H_{1}$ and $H_{2}$, respectively, and $A: H_{1} \rightarrow H_{2}$ is an operator. It is worth noting that a special case of problem (SFP) is the convexly constrained linear inverse problem in the finite dimensional Hilbert space [6]:

(CLIP) Find $\bar{x} \in C$ such that $A \bar{x}=b$, where $b \in H_{2}$.

Originally, problem (SFP) was considered in Euclidean spaces. (Note that if $H_{1}$ and $H_{2}$ are two Euclidean spaces, then $A$ is a matrix.) In 1994, problem (SFP) in finite dimensional Hilbert spaces was first introduced by Censor and Elfving [1] for modeling inverse problems which arise from medical image reconstruction. Since then, many researchers have

(อ2013 Chuang; licensee Springer. This is an Open Access article distributed under the terms of the Creative Commons Attribution License (http://creativecommons.org/licenses/by/2.0), which permits unrestricted use, distribution, and reproduction in any medium, provided the original work is properly cited. 
studied (SFP) in finite dimensional or infinite dimensional Hilbert spaces. For example, one can see $[2,7-16]$ and related literature.

In 2002, Byrne [2] first introduced the following recursive procedure:

$$
x_{n+1}=P_{C}\left(x_{n}-\rho_{n} A^{*}\left(I-P_{Q}\right) A x_{n}\right),
$$

where the stepsize $\tau_{n}$ is chosen in the interval $\left(0,2 /\|A\|^{2}\right)$, and $P_{C}$ and $P_{Q}$ are the metric projections onto $C \subseteq \mathbb{R}^{n}$ and $Q \subseteq \mathbb{R}^{m}$, respectively. This algorithm is called $C Q$ algorithm. Note that $A$ may be not invertible. In 2010, Wang and Xu [11] modified Byrne's CQ algorithm and gave a weak convergence theorem in infinite dimensional Hilbert spaces.

In 2004, motivated by the works on CQ algorithm (1.1), Yang [14] considered (SFP) under the following conditions:

$$
C:=\left\{x \in \mathbb{R}^{n}: c(x) \leq 0\right\} \text { and } Q:=\left\{x \in \mathbb{R}^{m}: q(x) \leq 0\right\}
$$

where $c: \mathbb{R}^{n} \rightarrow \mathbb{R}$ and $q: \mathbb{R}^{m} \rightarrow \mathbb{R}$ are convex and lower semicontinuous functions. In fact, Yang [14] studied the following problem, and we call this problem the relaxed split feasibility problem:

(RSFP) Find $\bar{x} \in \mathbb{R}^{n}$ such that $c(\bar{x}) \leq 0$ and $q(A \bar{x}) \leq 0$.

In 2010, Xu [13] modified and extended Yang's algorithm and gave a weak convergence theorem in infinite dimensional Hilbert spaces.

On the other hand, let $H$ be a real Hilbert space, and $B$ be a set-valued mapping with domain $\mathcal{D}(B):=\{x \in H: B(x) \neq \emptyset\}$. Recall that $B$ is called monotone if $\langle u-v, x-y\rangle \geq 0$ for any $u \in B x$ and $v \in B y ; B$ is maximal monotone if its graph $\{(x, y): x \in \mathcal{D}(B), y \in B x\}$ is not properly contained in the graph of any other monotone mapping. An important problem for set-valued monotone mappings is to find $\bar{x} \in H$ such that $0 \in B \bar{x}$. Here, $\bar{x}$ is called a zero point of $B$. A well-known method for approximating a zero point of a maximal monotone mapping defined in a real Hilbert space is the proximal point algorithm first introduced by Martinet [17] and generated by Rockafellar [18]. This is an iterative procedure, which generates $\left\{x_{n}\right\}$ by $x_{1}=x \in H$ and

$$
x_{n+1}=J_{\beta_{n}}^{B} x_{n}, \quad n \in \mathbb{N},
$$

where $\left\{\beta_{n}\right\} \subseteq(0, \infty), B$ is a maximal monotone mapping in a real Hilbert space, and $J_{r}^{B}$ is the resolvent mapping of $B$ defined by $J_{r}^{B}=(I+r B)^{-1}$ for each $r>0$. In 1976, Rockafellar [18] proved the following in the Hilbert space setting: If the solution set $B^{-1}(0)$ is nonempty and $\liminf _{n \rightarrow \infty} \beta_{n}>0$, then the sequence $\left\{x_{n}\right\}$ in (1.2) converges weakly to an element of $B^{-1}(0)$. In particular, if $B$ is the subdifferential $\partial f$ of a proper lower semicontinuous and convex function $f: H \rightarrow \mathbb{R}$, then (1.2) is reduced to

$$
x_{n+1}=\arg \min _{y \in H}\left\{f(y)+\frac{1}{2 \beta_{n}}\left\|y-x_{n}\right\|^{2}\right\}, \quad n \in \mathbb{N} .
$$

In this case, $\left\{x_{n}\right\}$ converges weakly to a minimizer of $f$. Later, many researchers have studied the convergence theorems of the proximal point algorithm in Hilbert spaces. For examples, one can refer to [19-24] and references therein. 
Let $H_{1}$ and $H_{2}$ be two real Hilbert spaces, $B_{1}: H_{1} \multimap H_{1}$ and $B_{2}: H_{2} \multimap H_{2}$ be two setvalued maximal monotone mappings, $A: H_{1} \rightarrow H_{2}$ be a linear and bounded operator, and $A^{*}$ be the adjoint of $A$. In this paper, motivated by the works in $[13,14]$ and related literature, we consider the following split variational inclusion problem:

(SFVIP) Find $\bar{x} \in H_{1}$ such that $0 \in B_{1}(\bar{x})$ and $0 \in B_{2}(A \bar{x})$.

Clearly, we know that the following split variational inclusion problem (SFVIP) is a generalization of variational inclusion problem. Further, we observed that problem (SFVIP) was introduced by Moudafi [25], and Moudafi [25] gave a weak convergence theorem for problem (SFVIP). The following is an iteration process given by Moudafi [25]:

$$
x_{n+1}:=J_{\lambda}^{B_{1}}\left(x_{n}+\gamma A^{*}\left(J_{\lambda}^{B_{2}}-I\right) A x_{n}\right) .
$$

It is worth noting that $\lambda$ and $\gamma$ are fixed numbers. Hence, it is important to establish generalized iteration processes and the related strong convergence theorems for problem (SFVIP).

Besides, we know that the following problems are special cases of problem (SFVIP).

(SFOP) Find $\bar{x} \in H_{1}$ such that $f(\bar{x})=\min _{y \in H_{1}} f(y)$ and $g(A \bar{x})=\min _{y \in H_{2}} g(z)$, where $f: H_{1} \rightarrow \mathbb{R}$ and $g: H_{2} \rightarrow \mathbb{R}$ are two proper, lower semicontinuous, and convex functions.

(SFP) Find $\bar{x} \in H_{1}$ such that $\bar{x} \in C$ and $A \bar{x} \in Q$, where $C$ and $Q$ are two nonempty closed convex subsets of real Hilbert spaces $H_{1}$ and $H_{2}$, respectively.

In this paper, we first consider a split variational inclusion problem and give several strong convergence theorems in Hilbert spaces, like the Halpern-Mann type iteration method, the regularized iteration method. As applications, we consider algorithms for a split feasibility problem and a split optimization problem and give strong convergence theorems for these problems in Hilbert spaces. Our results for the split feasibility problem improve the related results in the literature.

\section{Preliminaries}

Throughout this paper, let $\mathbb{N}$ be the set of positive integers and let $\mathbb{R}$ be the set of real numbers. Let $H$ be a (real) Hilbert space with the inner product $\langle\cdot, \cdot\rangle$ and the norm $\|\cdot\|$, respectively. We denote the strong convergence and the weak convergence of $\left\{x_{n}\right\}$ to $x \in H$ by $x_{n} \rightarrow x$ and $x_{n} \rightarrow x$, respectively. From [26], for each $x, y \in H$ and $\lambda \in[0,1]$, we have

$$
\|\lambda x+(1-\lambda) y\|^{2}=\lambda\|x\|^{2}+(1-\lambda)\|y\|^{2}-\lambda(1-\lambda)\|x-y\|^{2} .
$$

Hence, we also have

$$
2\langle x-y, u-v\rangle=\|x-v\|^{2}+\|y-u\|^{2}-\|x-u\|^{2}-\|y-v\|^{2}
$$

for all $x, y, u, v \in H$. Furthermore, we know that

$$
\|\alpha x+\beta y+\gamma z\|^{2}=\alpha\|x\|^{2}+\beta\|y\|^{2}+\gamma\|z\|^{2}-\alpha \beta\|x-y\|^{2}-\alpha \gamma\|x-z\|^{2}-\beta \gamma\|y-z\|^{2}
$$

for each $x, y, z \in H$ and $\alpha, \beta, \gamma \in[0,1]$ with $\alpha+\beta+\gamma=1$ [27]. 
Lemma 2.1 [28] Let $H$ be a (real) Hilbert space, and let $x, y \in H$. Then $\|x+y\|^{2} \leq\|x\|^{2}+$ $2\langle y, x+y\rangle$.

Let $C$ be a nonempty closed convex subset of a real Hilbert space $H$, and let $T: C \rightarrow H$ be a mapping. Let $\operatorname{Fix}(T):=\{x \in C: T x=x\}$. Then $T$ is said to be a nonexpansive mapping if $\|T x-T y\| \leq\|x-y\|$ for every $x, y \in C$. $T$ is said to be a quasi-nonexpansive mapping if $\operatorname{Fix}(T) \neq \emptyset$ and $\|T x-y\| \leq\|x-y\|$ for every $x \in C$ and $y \in \operatorname{Fix}(T)$. It is easy to see that Fix $(T)$ is a closed convex subset of $C$ if $T$ is a quasi-nonexpansive mapping. Besides, $T$ is said to be a firmly nonexpansive mapping if $\|T x-T y\|^{2} \leq\langle x-y, T x-T y\rangle$ for every $x, y \in C$, that is, $\|T x-T y\|^{2} \leq\|x-y\|^{2}-\|(I-T) x-(I-T) y\|^{2}$ for every $x, y \in C$.

Lemma 2.2 [29] Let $C$ be a nonempty closed convex subset of a real Hilbert space H. Let $T: C \rightarrow H$ be a nonexpansive mapping, and let $\left\{x_{n}\right\}$ be a sequence in $C$. If $x_{n} \rightarrow w$ and $\lim _{n \rightarrow \infty}\left\|x_{n}-T x_{n}\right\|=0$, then $T w=w$.

Let $C$ be a nonempty closed convex subset of a real Hilbert space $H$. Then, for each $x \in H$, there is a unique element $\bar{x} \in C$ such that $\|x-\bar{x}\|=\min _{y \in C}\|x-y\|$. Here, we set $P_{C} x=\bar{x}$ and $P_{C}$ is said to be the metric projection from $H$ onto $C$.

Lemma 2.3 [30] Let $C$ be a nonempty closed convex subset of a Hilbert space H. Let $P_{C}$ be the metric projection from $H$ onto $C$. Then, for each $x \in H$ and $z \in C$, we know that $z=P_{C} x$ if and only if $\langle x-z, z-y\rangle \geq 0$ for all $y \in C$.

The following result is an important tool in this paper. For similar results, one can see [31].

Lemma 2.4 Let $H$ be a real Hilbert space. Let $B: H \multimap H$ be a set-valued maximal monotone mapping, $\beta>0$, and let $J_{\beta}^{B}$ be a resolvent mapping of $B$.

(i) For each $\beta>0, J_{\beta}^{B}$ is a single-valued and firmly nonexpansive mapping;

(ii) $\mathcal{D}\left(J_{\beta}^{B}\right)=H$ and $\operatorname{Fix}\left(J_{\beta}^{B}\right)=\{x \in \mathcal{D}(B): 0 \in B x\}$;

(iii) $\left\|x-J_{\beta}^{B} x\right\| \leq\left\|x-J_{\gamma}^{B} x\right\|$ for all $0<\beta \leq \gamma$ and for all $x \in H$;

(iv) $\left(I-J_{\beta}^{B}\right)$ is a firmly nonexpansive mapping for each $\beta>0$;

(v) Suppose that $B^{-1}(0) \neq \emptyset$. Then $\left\|x-J_{\beta}^{B} x\right\|^{2}+\left\|J_{\beta}^{B} x-\bar{x}\right\|^{2} \leq\|x-\bar{x}\|^{2}$ for each $x \in H$, each $\bar{x} \in B^{-1}(0)$, and each $\beta>0$.

(vi) Suppose that $B^{-1}(0) \neq \emptyset$. Then $\left\langle x-J_{\beta}^{B} x, J_{\beta}^{B} x-w\right\rangle \geq 0$ for each $x \in H$ and each $w \in B^{-1}(0)$, and each $\beta>0$.

Lemma 2.5 Let $H_{1}$ and $H_{2}$ be two real Hilbert spaces, $A: H_{1} \rightarrow H_{2}$ be a linear operator, and $A^{*}$ be the adjoint of $A$, and let $\beta>0$ be fixed. Let $B: H_{2} \multimap H_{2}$ be a set-valued maximal monotone mapping, and let $J_{\beta}^{B}$ be a resolvent mapping of $B$. Let $T: H_{1} \rightarrow H_{1}$ be defined by $T x:=A^{*}\left(I-J_{\beta}^{B}\right) A x$ for each $x \in H_{1}$. Then

(i) $\left\|\left(I-J_{\beta}^{B}\right) A x-\left(I-J_{\beta}^{B}\right) A y\right\|^{2} \leq\langle T x-T y, x-y\rangle$ for all $x, y \in H_{1}$;

(ii) $\left\|A^{*}\left(I-J_{\beta}^{B}\right) A x-A^{*}\left(I-J_{\beta}^{B}\right) A y\right\|^{2} \leq\|A\|^{2} \cdot\langle T x-T y, x-y\rangle$ for all $x, y \in H_{1}$.

Proof (i) By Lemma 2.4,

$$
\begin{aligned}
\langle T x-T y, x-y\rangle & =\left\langle A^{*}\left(I-J_{\beta}^{B}\right) A x-A^{*}\left(I-J_{\beta}^{B}\right) A y, x-y\right\rangle \\
& =\left\langle\left(I-J_{\beta}^{B}\right) A x-\left(I-J_{\beta}^{B}\right) A y, A x-A y\right\rangle \\
& \geq\left\|\left(I-J_{\beta}^{B}\right) A x-\left(I-J_{\beta}^{B}\right) A y\right\|^{2}
\end{aligned}
$$


for all $x, y \in H_{1}$. (ii) Further, we have

$$
\begin{aligned}
\left\|A^{*}\left(I-J_{\beta}^{B}\right) A x-A^{*}\left(I-J_{\beta}^{B}\right) A y\right\|^{2} & \leq\|A\|^{2} \cdot\left\|\left(I-J_{\beta}^{B}\right) A x-\left(I-J_{\beta}^{B}\right) A y\right\|^{2} \\
& \leq\|A\|^{2} \cdot\langle T x-T y, x-y\rangle
\end{aligned}
$$

for all $x, y \in H_{1}$. Therefore, the proof is completed.

Lemma 2.6 Let $H_{1}$ and $H_{2}$ be two real Hilbert spaces, $A: H_{1} \rightarrow H_{2}$ be a linear operator, and $A^{*}$ be the adjoint of $A$, and let $\beta>0$ be fixed, and let $\rho \in\left(0, \frac{2}{\|A\|^{2}}\right)$. Let $B_{2}: H_{2} \multimap H_{2}$ be a set-valued maximal monotone mapping, and let $J_{\beta}^{B_{2}}$ be a resolvent mapping of $B_{2}$. Then

$$
\begin{aligned}
& \left\|\left[x-\rho A^{*}\left(I-J_{\beta}^{B_{2}}\right) A x\right]-\left[y-\rho A^{*}\left(I-J_{\beta}^{B_{2}}\right) A y\right]\right\|^{2} \\
& \quad \leq\|x-y\|^{2}-\left(2 \rho-\rho^{2}\|A\|^{2}\right)\left\|\left(I-J_{\beta}^{B_{2}}\right) A x-\left(I-J_{\beta}^{B_{2}}\right) A y\right\|^{2}
\end{aligned}
$$

for all $x, y \in H_{1}$. Furthermore, $I-\rho A^{*}\left(I-J_{\beta}^{B_{2}}\right) A$ is a nonexpansive mapping.

Proof For all $x, y \in H_{1}$, we have

$$
\begin{aligned}
\left\|\left[x-\rho A^{*}\left(I-J_{\beta}^{B_{2}}\right) A x\right]-\left[y-\rho A^{*}\left(I-J_{\beta}^{B_{2}}\right) A y\right]\right\|^{2} \\
=\|x-y\|^{2}-2 \rho\left(x-y, A^{*}\left(I-J_{\beta}^{B_{2}}\right) A x-A^{*}\left(I-J_{\beta}^{B_{2}}\right) A y\right\rangle \\
\quad+\rho^{2}\left\|A^{*}\left(I-J_{\beta}^{B_{2}}\right) A x-A^{*}\left(I-J_{\beta}^{B_{2}}\right) A y\right\|^{2} \\
=\|x-y\|^{2}-2 \rho\left\langle A x-A y,\left(I-J_{\beta}^{B_{2}}\right) A x-\left(I-J_{\beta}^{B_{2}}\right) A y\right\rangle \\
\quad+\rho^{2}\left\|A^{*}\left(I-J_{\beta}^{B_{2}}\right) A x-A^{*}\left(I-J_{\beta}^{B_{2}}\right) A y\right\|^{2} .
\end{aligned}
$$

Hence, it follows from (2.1) and Lemma 2.4 that

$$
\begin{aligned}
& \left\|\left[x-\rho A^{*}\left(I-J_{\beta}^{B_{2}}\right) A x\right]-\left[y-\rho A^{*}\left(I-J_{\beta}^{B_{2}}\right) A y\right]\right\|^{2} \\
& \leq\|x-y\|^{2}-2 \rho\left\|\left(I-J_{\beta}^{B_{2}}\right) A x-\left(I-J_{\beta}^{B_{2}}\right) A y\right\|^{2} \\
& \quad+\rho^{2}\left\|A^{*}\left(I-J_{\beta}^{B_{2}}\right) A x-A^{*}\left(I-J_{\beta}^{B_{2}}\right) A y\right\|^{2} \\
& \leq\|x-y\|^{2}-\left(2 \rho-\rho^{2}\|A\|^{2}\right)\left\|\left(I-J_{\beta}^{B_{2}}\right) A x-\left(I-J_{\beta}^{B_{2}}\right) A y\right\|^{2}
\end{aligned}
$$

for all $x, y \in H_{1}$. Therefore, the proof is completed.

The following is a very important result for various strong convergence theorems. Recently, many researchers have studied Halpern's type strong convergence theorems by using the following lemma and got many generalized results. For examples, one can see [32, 33]. In this paper, we also use this result to get our strong convergence theorems, and our results for the split feasibility problem improve the results in the literature.

Lemma 2.7 [34] Let $\left\{a_{n}\right\}$ be a sequence of real numbers such that there exists a subsequence $\left\{n_{i}\right\}$ of $\{n\}$ such that $a_{n_{i}}<a_{n_{i}+1}$ for all $i \in \mathbb{N}$. Then there exists a nondecreasing sequence $\left\{m_{k}\right\} \subseteq \mathbb{N}$ such that $m_{k} \rightarrow \infty, a_{m_{k}} \leq a_{m_{k}+1}$ and $a_{k} \leq a_{m_{k+1}}$ are satisfied by all (sufficiently large) numbers $k \in \mathbb{N}$. In fact, $m_{k}=\max \left\{j \leq k: a_{j}<a_{j+1}\right\}$. 
Lemma 2.8 [35] Let $\left\{a_{n}\right\}_{n \in \mathbb{N}}$ be a sequence of nonnegative real numbers, $\left\{\alpha_{n}\right\}$ be a sequence of real numbers in $[0,1]$ with $\sum_{n=1}^{\infty} \alpha_{n}=\infty,\left\{u_{n}\right\}$ be a sequence of nonnegative real numbers with $\sum_{n=1}^{\infty} u_{n}<\infty,\left\{t_{n}\right\}$ be a sequence of real numbers with $\lim \sup t_{n} \leq 0$. Suppose that $a_{n+1} \leq\left(1-\alpha_{n}\right) a_{n}+\alpha_{n} t_{n}+u_{n}$ for each $n \in \mathbb{N}$. Then $\lim _{n \rightarrow \infty} a_{n}=0$.

\section{Halpern-Mann type algorithm with perturbations}

In this section, we first give the following result.

Lemma 3.1 Let $H_{1}$ and $H_{2}$ be two real Hilbert spaces, $A: H_{1} \rightarrow H_{2}$ be a linear and bounded operator, and let $A^{*}$ denote the adjoint of $A$. Let $B_{1}: H_{1} \multimap H_{1}$, and $B_{2}: H_{2} \multimap H_{2}$ be two set-valued maximal monotone mappings, and let $\beta>0$ and $\gamma>0$. Given any $\bar{x} \in H_{1}$.

(i) If $\bar{x}$ is a solution of (SFVIP), then $J_{\beta}^{B_{1}}\left(\bar{x}-\gamma A^{*}\left(I-J_{\beta}^{B_{2}}\right) A \bar{x}\right)=\bar{x}$.

(ii) Suppose that $J_{\beta}^{B_{1}}\left(\bar{x}-\gamma A^{*}\left(I-J_{\beta_{n}}^{B_{2}}\right) A \bar{x}\right)=\bar{x}$ and the solution set of (SFVIP) is nonempty. Then $\bar{x}$ is a solution of (SFVIP).

Proof (i) Suppose that $\bar{x} \in H_{1}$ is a solution of (SFVIP). Then $\bar{x} \in B_{1}^{-1}(0)$ and $A \bar{x} \in B_{2}^{-1}(0)$. By Lemma 2.4, it is easy to see that

$$
J_{\beta}^{B_{1}}\left(\bar{x}-\gamma A^{*}\left(I-J_{\beta}^{B_{2}}\right) A \bar{x}\right)=J_{\beta}^{B_{1}}\left(\bar{x}-\gamma A^{*}\left(A \bar{x}-J_{\beta}^{B_{2}} A \bar{x}\right)\right)=J_{\beta}^{B_{1}}(\bar{x})=\bar{x} .
$$

(ii) Suppose that $\bar{w}$ is a solution of (SFVIP) and $J_{\beta}^{B_{1}}\left(\bar{x}-\gamma A^{*}\left(I-J_{\beta}^{B_{2}}\right) A \bar{x}\right)=\bar{x}$. By Lemma 2.4,

$$
\left\langle\left(\bar{x}-\gamma A^{*}\left(I-J_{\beta}^{B_{2}}\right) A \bar{x}\right)-\bar{x}, \bar{x}-w\right\rangle \geq 0 \quad \text { for each } w \in B_{1}^{-1}(0) .
$$

That is,

$$
\left\langle A^{*}\left(I-J_{\beta}^{B_{2}}\right) A \bar{x}, \bar{x}-w\right\rangle \leq 0 \quad \text { for each } w \in B_{1}^{-1}(0) .
$$

By (3.1) and $A^{*}$ is the adjoint of $A$,

$$
\left\langle A \bar{x}-J_{\beta}^{B_{2}} A \bar{x}, A \bar{x}-A w\right\rangle \leq 0 \quad \text { for each } w \in B_{1}^{-1}(0) .
$$

On the other hand, by Lemma 2.4 again,

$$
\left\langle A \bar{x}-J_{\beta}^{B_{2}} A \bar{x}, \nu-J_{\beta}^{B_{2}} A \bar{x}\right\rangle \leq 0 \quad \text { for each } v \in B_{2}^{-1}(0) .
$$

By (3.2) and (3.3),

$$
\left\langle A \bar{x}-J_{\beta}^{B_{2}} A \bar{x}, v-J_{\beta}^{B_{2}} A \bar{x}+A \bar{x}-A w\right\rangle \leq 0
$$

for each $w \in B_{1}^{-1}(0)$ and each $v \in B_{2}^{-1}(0)$. That is,

$$
\left\|A \bar{x}-J_{\beta}^{B_{2}} A \bar{x}\right\|^{2} \leq\left\langle A \bar{x}-J_{\beta}^{B_{2}} A \bar{x}, A w-v\right\rangle
$$

for each $w \in B_{1}^{-1}(0)$ and each $v \in B_{2}^{-1}(0)$. Since $\bar{w}$ is a solution of (SFVIP), $\bar{w} \in B_{1}^{-1}(0)$ and $A \bar{w} \in B_{2}^{-1}(0)$. So, it follows from (3.5) that $A \bar{x}=J_{\beta}^{B_{2}} A \bar{x}$. So, $A \bar{x} \in \operatorname{Fix}\left(J_{\beta}^{B_{2}}\right)=B_{2}^{-1}(0)$. Further,

$$
\bar{x}=J_{\beta}^{B_{1}}\left(\bar{x}-\gamma A^{*}\left(I-J_{\beta}^{B_{2}}\right) A \bar{x}\right)=J_{\beta}^{B_{1}}(\bar{x}) .
$$

Then $\bar{x} \in \operatorname{Fix}\left(J_{\beta}^{B_{1}}\right)=B_{1}^{-1}(0)$. Therefore, $\bar{x}$ is a solution of (SFVIP). 
Theorem 3.1 Let $H_{1}$ and $H_{2}$ be two real Hilbert spaces, $A: H_{1} \rightarrow H_{2}$ be a linear and bounded operator, and let $A^{*}$ denote the adjoint of $A$. Let $B_{1}: H_{1} \multimap H_{1}$ and $B_{2}: H_{2} \multimap H_{2}$ be two set-valued maximal monotone mappings. Let $\left\{a_{n}\right\},\left\{b_{n}\right\},\left\{c_{n}\right\}$, and $\left\{d_{n}\right\}$ be sequences of real numbers in $[0,1]$ with $a_{n}+b_{n}+c_{n}+d_{n}=1$ and $0<a_{n}<1$ for each $n \in \mathbb{N}$. Let $\left\{\beta_{n}\right\}$ be a sequence in $(0, \infty)$. Let $\left\{v_{n}\right\}$ be a bounded sequence in $H$. Let $u \in H$ be fixed. Let $\left\{\rho_{n}\right\} \subseteq\left(0, \frac{2}{\|A\|^{2}+1}\right)$. Let $\Omega$ be the solution set of (SFVIP) and suppose that $\Omega \neq \emptyset$. Let $\left\{x_{n}\right\}$ be defined by

$$
x_{n+1}:=a_{n} u+b_{n} x_{n}+c_{n} J_{\beta_{n}}^{B_{1}}\left[x_{n}-\rho_{n} A^{*}\left(I-J_{\beta_{n}}^{B_{2}}\right) A x_{n}\right]+d_{n} v_{n}
$$

for each $n \in \mathbb{N}$. Assume that:

(i) $\lim _{n \rightarrow \infty} a_{n}=\lim _{n \rightarrow \infty} \frac{d_{n}}{a_{n}}=0 ; \sum_{n=1}^{\infty} a_{n}=\infty ; \sum_{n=1}^{\infty} d_{n}<\infty$;

(ii) $\liminf _{n \rightarrow \infty} c_{n} \rho_{n}>0, \liminf _{n \rightarrow \infty} b_{n} c_{n}>0, \liminf _{n \rightarrow \infty} \beta_{n}>0$.

Then $\lim _{n \rightarrow \infty} x_{n}=\bar{x}$, where $\bar{x}=P_{\Omega} u$.

Proof Let $\bar{x}=P_{\Omega} u$, where $P_{\Omega}$ is the metric projection from $H_{1}$ onto $\Omega$. Then, for each $n \in \mathbb{N}$, it follows from Lemma 2.6 that

$$
\begin{aligned}
& \left\|x_{n+1}-\bar{x}\right\| \\
& \leq a_{n}\|u-\bar{x}\|+b_{n}\left\|x_{n}-\bar{x}\right\|+d_{n}\left\|v_{n}-\bar{x}\right\| \\
& +c_{n}\left\|J_{\beta_{n}}^{B_{1}}\left[x_{n}-\rho_{n} A^{*}\left(I-J_{\beta_{n}}^{B_{2}}\right) A x_{n}\right]-\bar{x}\right\| \\
& \leq a_{n}\|u-\bar{x}\|+b_{n}\left\|x_{n}-\bar{x}\right\|+d_{n}\left\|v_{n}-\bar{x}\right\|+c_{n} \|\left[x_{n}-\rho_{n} A^{*}\left(I-J_{\beta_{n}}^{B_{2}}\right) A x_{n}\right] \\
& -\left[\bar{x}-\rho_{n} A^{*}\left(I-J_{\beta_{n}}^{B_{2}}\right) A \bar{x}\right] \| \\
& \leq a_{n}\|u-\bar{x}\|+\left(b_{n}+c_{n}\right)\left\|x_{n}-\bar{x}\right\|+d_{n}\left\|v_{n}-\bar{x}\right\| .
\end{aligned}
$$

This implies that $\left\{x_{n}\right\}$ is a bounded sequence. Besides, by Lemmas 2.4 and 2.6, we have

$$
\begin{aligned}
& \left\|J_{\beta_{n}}^{B_{1}}\left[x_{n}-\rho_{n} A^{*}\left(I-J_{\beta_{n}}^{B_{2}}\right) A x_{n}\right]-\bar{x}\right\|^{2} \\
& \quad \leq\left\|\left[x_{n}-\rho_{n} A^{*}\left(I-J_{\beta_{n}}^{B_{2}}\right) A x_{n}\right]-\left[\bar{x}-\rho_{n} A^{*}\left(I-J_{\beta_{n}}^{B_{2}}\right) A \bar{x}\right]\right\| \\
& \quad \leq\left\|x_{n}-\bar{x}\right\|^{2}-\left(2 \rho_{n}-\rho_{n}^{2}\|A\|^{2}\right)\left\|\left(I-J_{\beta_{n}}^{B_{2}}\right) A x_{n}-\left(I-J_{\beta_{n}}^{B_{2}}\right) A \bar{x}\right\|^{2} \\
& \quad=\left\|x_{n}-\bar{x}\right\|^{2}-\left(2 \rho_{n}-\rho_{n}^{2}\|A\|^{2}\right)\left\|\left(I-J_{\beta_{n}}^{B_{2}}\right) A x_{n}\right\|^{2} .
\end{aligned}
$$

Hence, it follows from Lemma 2.1 that

$$
\begin{aligned}
\left\|x_{n+1}-\bar{x}\right\|^{2} \\
=\left\|a_{n} u+b_{n} x_{n}+c_{n} J_{\beta_{n}}^{B_{1}}\left[x_{n}-\rho_{n} A^{*}\left(I-J_{\beta_{n}}^{B_{2}}\right) A x_{n}\right]+d_{n} v_{n}-\bar{x}\right\|^{2} \\
\leq\left\|b_{n}\left(x_{n}-\bar{x}\right)+c_{n}\left(J_{\beta_{n}}^{B_{1}}\left[x_{n}-\rho_{n} A^{*}\left(I-J_{\beta_{n}}^{B_{2}}\right) A x_{n}\right]-\bar{x}\right)+d_{n}\left(v_{n}-\bar{x}\right)\right\|^{2} \\
\quad+2 a_{n}\left\langle u-\bar{x}, x_{n+1}-\bar{x}\right\rangle \\
=\left(1-a_{n}\right)^{2}\left\|b_{n}^{\prime}\left(x_{n}-\bar{x}\right)+c_{n}^{\prime}\left(J_{\beta_{n}}^{B_{1}}\left[x_{n}-\rho_{n} A^{*}\left(I-J_{\beta_{n}}^{B_{2}}\right) A x_{n}\right]-\bar{x}\right)+d_{n}^{\prime}\left(v_{n}-\bar{x}\right)\right\|^{2} \\
\quad+2 a_{n}\left\langle u-\bar{x}, x_{n+1}-\bar{x}\right\rangle,
\end{aligned}
$$


where $b_{n}^{\prime}:=\frac{b_{n}}{b_{n}+c_{n}+d_{n}}, c_{n}^{\prime}:=\frac{c_{n}}{b_{n}+c_{n}+d_{n}}, d_{n}^{\prime}:=\frac{d_{n}}{b_{n}+c_{n}+d_{n}}$. Further, by (3.6) and (3.7), we have

$$
\begin{aligned}
& \left\|x_{n+1}-\bar{x}\right\|^{2} \\
& \leq \quad b_{n}\left\|x_{n}-\bar{x}\right\|^{2}+c_{n}\left\|J_{\beta_{n}}^{B_{1}}\left[x_{n}-\rho_{n} A^{*}\left(I-J_{\beta_{n}}^{B_{2}}\right) A x\right]-\bar{x}\right\|^{2}+d_{n}\left\|v_{n}-\bar{x}\right\|^{2} \\
& \quad+2 a_{n}\left\langle u-\bar{x}, x_{n+1}-v\right\rangle-b_{n} c_{n}\left\|x_{n}-J_{\beta_{n}}^{B_{1}}\left[x_{n}-\rho_{n} A^{*}\left(I-J_{\beta_{n}}^{B_{2}}\right) A x\right]\right\|^{2} \\
& \leq b_{n}\left\|x_{n}-\bar{x}\right\|^{2}+c_{n}\left(\left\|x_{n}-\bar{x}\right\|^{2}-\left(2 \rho_{n}-\rho_{n}^{2}\|A\|^{2}\right)\left\|A x_{n}-J_{\beta_{n}}^{B_{2}} A x_{n}\right\|^{2}\right) \\
& \quad+d_{n}\left\|v_{n}-\bar{x}\right\|^{2}+2 a_{n}\left\langle u-\bar{x}, x_{n+1}-v\right\rangle-b_{n} c_{n}\left\|x_{n}-J_{\beta_{n}}^{B_{1}}\left[x_{n}-\rho_{n} A^{*}\left(I-J_{\beta_{n}}^{B_{2}}\right) A x\right]\right\|^{2} \\
& =\left(b_{n}+c_{n}\right)\left\|x_{n}-\bar{x}\right\|^{2}+d_{n}\left\|v_{n}-\bar{x}\right\|^{2}+2 a_{n}\left\langle u-\bar{x}, x_{n+1}-\bar{x}\right\rangle \\
& \quad-c_{n}\left(2 \rho_{n}-\rho_{n}^{2}\|A\|^{2}\right)\left\|A x_{n}-J_{\beta_{n}}^{B_{2}} A x_{n}\right\|^{2} \\
& \quad-b_{n} c_{n}\left\|x_{n}-J_{\beta_{n}}^{B_{1}}\left[x_{n}-\rho_{n} A^{*}\left(I-J_{\beta_{n}}^{B_{2}}\right) A x\right]\right\|^{2} .
\end{aligned}
$$

Since $\liminf \operatorname{in}_{n \rightarrow \infty} \beta_{n}>0$, we may assume that $\beta_{n}>\beta>0$ for each $n \in \mathbb{N}$. Next, we consider two cases.

Case 1: There exists a natural number $N$ such that $\left\|x_{n+1}-\bar{x}\right\| \leq\left\|x_{n}-\bar{x}\right\|$ for each $n \geq N$. So, $\lim _{n \rightarrow \infty}\left\|x_{n}-\bar{x}\right\|$ exists. Hence, it follows from (3.8) and (i) that

$$
\lim _{n \rightarrow \infty} c_{n}\left(2 \rho_{n}-\rho_{n}^{2}\|A\|^{2}\right)\left\|A x_{n}-J_{\beta_{n}}^{B_{2}} A x_{n}\right\|^{2}=0
$$

Clearly, $c_{n}\left(2 \rho_{n}-\rho_{n}^{2}\|A\|^{2}\right) \geq \frac{c_{n} \rho_{n}}{\|A\|^{2}+1}$. Since $\liminf _{n \rightarrow \infty} c_{n} \rho_{n}>0$, we have

$$
\lim _{n \rightarrow \infty}\left\|A x_{n}-J_{\beta_{n}}^{B_{2}} A x_{n}\right\|=0
$$

By (3.9) and Lemma 2.4,

$$
\lim _{n \rightarrow \infty}\left\|A x_{n}-J_{\beta}^{B_{2}} A x_{n}\right\|=0
$$

Similarly, we know that

$$
\lim _{n \rightarrow \infty}\left\|x_{n}-J_{\beta_{n}}^{B_{1}}\left[x_{n}-\rho_{n} A^{*}\left(I-J_{\beta_{n}}^{B_{2}}\right) A x_{n}\right]\right\|=0 .
$$

Further, there exists a subsequence $\left\{x_{n_{k}}\right\}$ of $\left\{x_{n}\right\}$ such that $x_{n_{k}} \rightarrow z$ for some $z \in C$ and

$$
\limsup _{n \rightarrow \infty}\left\langle u-\bar{x}, x_{n+1}-\bar{x}\right\rangle=\lim _{k \rightarrow \infty}\left\langle u-\bar{x}, x_{n_{k}}-\bar{x}\right\rangle=\langle u-\bar{x}, z-\bar{x}\rangle .
$$

Clearly, $A x_{n_{k}} \rightarrow A z$. By (3.10), Lemmas 2.2 and 2.4, we know that $A z \in B_{2}^{-1}(0)$. Besides, it follows from Lemma 2.4 that

$$
\left\|J_{\beta_{n}}^{B_{1}}\left[x_{n}-\rho_{n} A^{*}\left(I-J_{\beta_{n}}^{B_{2}}\right) A x_{n}\right]-J_{\beta_{n}}^{B_{1}} x_{n}\right\| \leq \rho_{n}\|A\| \cdot\left\|A x_{n}-J_{\beta_{n}}^{B_{2}} A x_{n}\right\| .
$$

By (3.9) and (3.13),

$$
\lim _{n \rightarrow \infty}\left\|J_{\beta_{n}}^{B_{1}}\left[x_{n}-\rho_{n} A^{*}\left(I-J_{\beta_{n}}^{B_{2}}\right) A x_{n}\right]-J_{\beta_{n}}^{B_{1}} x_{n}\right\|=0
$$


By (3.11) and (3.14),

$$
\lim _{n \rightarrow \infty}\left\|x_{n}-\int_{\beta_{n}}^{B_{1}} x_{n}\right\|=0
$$

By (3.15) and Lemma 2.4,

$$
\lim _{n \rightarrow \infty}\left\|x_{n}-J_{\beta}^{B_{1}} x_{n}\right\|=0
$$

Then it follows from (3.16) and Lemma 2.2 that $z \in B_{1}^{-1}(0)$. So, $z$ is a solution of (SFVIP). By (3.12) and Lemma 2.3,

$$
\limsup _{n \rightarrow \infty}\left\langle u-\bar{x}, x_{n+1}-\bar{x}\right\rangle \leq 0 .
$$

By assumptions, (3.8), (3.17), and Lemma 2.8, we know that $\lim _{n \rightarrow \infty} x_{n}=\bar{x}$.

Case 2: Suppose that there exists $\left\{n_{i}\right\}$ of $\{n\}$ such that $\left\|x_{n_{i}}-\bar{x}\right\| \leq\left\|x_{n_{i+1}}-\bar{x}\right\|$ for all $i \in \mathbb{N}$. By Lemma 2.7, there exists a nondecreasing sequence $\left\{m_{k}\right\}$ in $\mathbb{N}$ such that $m_{k} \rightarrow \infty$,

$$
\left\|x_{m_{k}}-\bar{x}\right\| \leq\left\|x_{m_{k}+1}-\bar{x}\right\| \quad \text { and } \quad\left\|x_{k}-\bar{x}\right\| \leq\left\|x_{m_{k}+1}-\bar{x}\right\|
$$

for all $k \in \mathbb{N}$. By (3.8) and (3.18), we have

$$
\begin{aligned}
\left\|x_{m_{k}}-\bar{x}\right\| \\
\leq \| \\
\leq x_{m_{k}+1}-\bar{x} \|^{2} \\
\leq\left(b_{m_{k}}+c_{m_{k}}\right)\left\|x_{m_{k}}-\bar{x}\right\|^{2}+d_{m_{k}}\left\|v_{m_{k}}-\bar{x}\right\|^{2}+2 a_{m_{k}}\left\langle u-\bar{x}, x_{m_{k}+1}-\bar{x}\right\rangle \\
\quad-c_{m_{k}}\left(2 \rho_{m_{k}}-\rho_{m_{k}}^{2}\|A\|^{2}\right)\left\|A x_{m_{k}}-J_{\beta_{m_{k}}}^{B_{2}} A x_{m_{k}}\right\|^{2} \\
\quad-b_{m_{k}} c_{m_{k}}\left\|x_{m_{k}}-J_{\beta_{m_{k}}}^{B_{1}}\left[x_{m_{k}}-\rho_{m_{k}} A^{*}\left(I-J_{\beta_{m_{k}}}^{B_{2}}\right) A x_{m_{k}}\right]\right\|^{2} .
\end{aligned}
$$

Following a similar argument as the proof of Case 1, we have

$$
\begin{aligned}
& \lim _{k \rightarrow \infty}\left\|x_{m_{k}}-J_{\beta_{m_{k}}}^{B_{1}}\left[x_{m_{k}}-\rho_{m_{k}} A^{*}\left(I-J_{\beta_{m_{k}}}^{B_{2}}\right) A x_{m_{k}}\right]\right\|=0, \\
& \lim _{k \rightarrow \infty}\left\|A x_{m_{k}}-J_{\beta}^{B_{2}} A x_{m_{k}}\right\|=\lim _{k \rightarrow \infty}\left\|x_{m_{k}}-J_{\beta}^{B_{1}} x_{m_{k}}\right\|=0
\end{aligned}
$$

and

$$
\limsup _{k \rightarrow \infty}\left\langle u-\bar{x}, x_{m_{k}+1}-\bar{x}\right\rangle \leq 0
$$

By (3.19),

$$
\left\|x_{m_{k}}-\bar{x}\right\|^{2} \leq \frac{d_{m_{k}}}{a_{m_{k}}}\left\|v_{m_{k}}-\bar{x}\right\|^{2}+2\left\langle u-\bar{x}, x_{m_{k}+1}-\bar{x}\right\rangle .
$$

By assumption, (3.22), and (3.23),

$$
\lim _{k \rightarrow \infty}\left\|x_{m_{k}}-\bar{x}\right\|=0
$$


Besides, we have

$$
\begin{aligned}
& \left\|x_{m_{k}+1}-x_{m_{k}}\right\| \\
& \quad \leq a_{m_{k}}\left\|u-x_{m_{k}}\right\|+c_{m_{k}}\left\|x_{m_{k}}-J_{\beta_{m_{k}}}^{B_{1}}\left[x_{m_{k}}-\rho_{m_{k}} A^{*}\left(I-J_{\beta_{m_{k}}}^{B_{2}}\right) A x_{m_{k}}\right]\right\| \\
& \quad+d_{m_{k}}\left\|v_{m_{k}}-x_{m_{k}}\right\| .
\end{aligned}
$$

By assumptions, (3.20), and (3.25),

$$
\lim _{k \rightarrow \infty}\left\|x_{m_{k}+1}-x_{m_{k}}\right\|=0
$$

By (3.24) and (3.26),

$$
\lim _{k \rightarrow \infty}\left\|x_{m_{k}+1}-\bar{x}\right\|=0
$$

By (3.18) and (3.27),

$$
\lim _{k \rightarrow \infty}\left\|x_{k}-\bar{x}\right\|=0
$$

Therefore, the proof is completed.

In Theorem 3.1, if we set $v_{n}=0$ and $d_{n}=0$ for each $n \in \mathbb{N}$, then we get the following result.

Corollary 3.1 Let $H_{1}$ and $H_{2}$ be two real Hilbert spaces, $A: H_{1} \rightarrow H_{2}$ be a linear and bounded operator, and let $A^{*}$ denote the adjoint of $A$. Let $B_{1}: H_{1} \multimap H_{1}$ and $B_{2}: H_{2} \multimap H_{2}$ be two set-valued maximal monotone mappings. Let $\left\{a_{n}\right\},\left\{b_{n}\right\}$, and $\left\{c_{n}\right\}$ be sequences of real numbers in $[0,1]$ with $a_{n}+b_{n}+c_{n}=1$ and $0<a_{n}<1$ for each $n \in \mathbb{N}$. Let $\left\{\beta_{n}\right\}$ be a sequence in $(0, \infty)$. Let $u \in H$ be fixed. Let $\left\{\rho_{n}\right\} \subseteq\left(0, \frac{2}{\|A\|^{2}+1}\right)$. Let $\Omega$ be the solution set of (SFVIP) and suppose that $\Omega \neq \emptyset$. Let $\left\{x_{n}\right\}$ be defined by

$$
x_{n+1}:=a_{n} u+b_{n} x_{n}+c_{n} J_{\beta_{n}}^{B_{1}}\left[x_{n}-\rho_{n} A^{*}\left(I-J_{\beta_{n}}^{B_{2}}\right) A x_{n}\right]
$$

for each $n \in \mathbb{N}$. Assume that $\lim _{n \rightarrow \infty} a_{n}=0, \sum_{n=1}^{\infty} a_{n}=\infty, \liminf _{n \rightarrow \infty} c_{n} \rho_{n}>0$, $\liminf _{n \rightarrow \infty} b_{n} c_{n}>0$, and $\liminf _{n \rightarrow \infty} \beta_{n}>0$. Then $\lim _{n \rightarrow \infty} x_{n}=\bar{x}$, where $\bar{x}=P_{\Omega} u$.

Further, we can get the following result by Corollary 3.1 and Lemma 2.8. In fact, Corollary 3.1 and Theorem 3.2 are equivalent.

Theorem 3.2 Let $H_{1}$ and $H_{2}$ be two real Hilbert spaces, $A: H_{1} \rightarrow H_{2}$ be a linear and bounded operator, and let $A^{*}$ denote the adjoint of $A$. Let $B_{1}: H_{1} \multimap H_{1}$ and $B_{2}: H_{2} \multimap H_{2}$ be two set-valued maximal monotone mappings. Let $\left\{a_{n}\right\},\left\{b_{n}\right\}$, and $\left\{c_{n}\right\}$ be sequences of real numbers in $[0,1]$ with $a_{n}+b_{n}+c_{n}=1$ and $0<a_{n}<1$ for each $n \in \mathbb{N}$. Let $\left\{\beta_{n}\right\}$ be a sequence in $(0, \infty)$. Let $\left\{v_{n}\right\}$ be a bounded sequence in $H$. Let $u \in H$ be fixed. Let $\left\{\rho_{n}\right\} \subseteq\left(0, \frac{2}{\|A\|^{2}+1}\right)$. Let $\Omega$ be the solution set of (SFVIP) and suppose that $\Omega \neq \emptyset$. Let $\left\{v_{n}\right\}$ be a bounded sequence. Let $\left\{x_{n}\right\}$ be defined by

$$
x_{n+1}:=a_{n} u+b_{n} x_{n}+c_{n} J_{\beta_{n}}^{B_{1}}\left[x_{n}-\rho_{n} A^{*}\left(I-J_{\beta_{n}}^{B_{2}}\right) A x_{n}\right]+v_{n}
$$


for each $n \in \mathbb{N}$. Assume that $\lim _{n \rightarrow \infty} a_{n}=0, \sum_{n=1}^{\infty} a_{n}=\infty, \sum_{n=1}^{\infty}\left\|v_{n}\right\|<\infty, \liminf _{n \rightarrow \infty} c_{n} \times$ $\rho_{n}>0, \liminf _{n \rightarrow \infty} b_{n} c_{n}>0$, and $\liminf _{n \rightarrow \infty} \beta_{n}>0$. Then $\lim _{n \rightarrow \infty} x_{n}=\bar{x}$, where $\bar{x}=P_{\Omega} u$.

Proof Let $\left\{y_{n}\right\}$ be defined by

$$
y_{n+1}:=a_{n} u+b_{n} y_{n}+c_{n} J_{\beta_{n}}^{B_{1}}\left[y_{n}-\rho_{n} A^{*}\left(I-J_{\beta_{n}}^{B_{2}}\right) A y_{n}\right] .
$$

By Corollary 3.1, $\lim _{n \rightarrow \infty} y_{n}=\bar{x}$, where $\bar{x}=P_{\Omega} u$. Besides, we know that

$$
\begin{aligned}
& \left\|x_{n+1}-y_{n+1}\right\| \\
& \quad \leq c_{n}\left\|J_{\beta_{n}}^{B_{1}}\left[x_{n}-\rho_{n} A^{*}\left(I-J_{\beta_{n}}^{B_{2}}\right) A x_{n}\right]-J_{\beta_{n}}^{B_{1}}\left[y_{n}-\rho_{n} A^{*}\left(I-J_{\beta_{n}}^{B_{2}}\right) A y_{n}\right]\right\| \\
& \quad+b_{n}\left\|x_{n}-y_{n}\right\|+\left\|v_{n}\right\| \\
& \leq \\
& \leq\left(b_{n}+c_{n}\right)\left\|x_{n}-y_{n}\right\|+\left\|v_{n}\right\| \\
& =\left(1-a_{n}\right)\left\|x_{n}-y_{n}\right\|+\left\|v_{n}\right\| .
\end{aligned}
$$

By (3.28) and Lemma 2.8, $\lim _{n \rightarrow \infty}\left\|x_{n}-y_{n}\right\|=0$. So, $\lim _{n \rightarrow \infty} x_{n}=\bar{x}$, where $\bar{x}=P_{\Omega} u$. Therefore, the proof is completed.

\section{Regularized method for (SFVIP)}

Lemma 4.1 Let $H_{1}$ and $H_{2}$ be two real Hilbert spaces, $A: H_{1} \rightarrow H_{2}$ be a linear and bounded operator, and let $A^{*}$ denote the adjoint of $A$. Let $B_{1}: H_{1} \multimap H_{1}$ and $B_{2}: H_{2} \multimap H_{2}$ be two setvalued maximal monotone mappings. Let $\beta>0, a \in(0,1)$, and $\rho \in\left(0,2 /\left(\|A\|^{2}+2\right)\right)$. Then

$$
\left\|J_{\beta}^{B_{1}}\left[(1-a \rho) x-\rho A^{*}\left(I-J_{\beta}^{B_{2}}\right) A x\right]-J_{\beta}^{B_{1}}\left[(1-a \rho) y-\rho A^{*}\left(I-J_{\beta}^{B_{2}}\right) A y\right]\right\| \leq(1-a \rho)\|x-y\|
$$

for all $x, y \in H_{1}$.

Proof For each $x, y \in H_{1}$, it follows from Lemma 2.4 and Lemma 2.5 that

$$
\begin{aligned}
&\left\|J_{\beta}^{B_{1}}\left((1-a \rho) x-\rho A^{*}\left(I-J_{\beta}^{B_{2}}\right) A x\right)-J_{\beta}^{B_{1}}\left((1-a \rho) y-\rho A^{*}\left(I-J_{\beta}^{B_{2}}\right) A y\right)\right\|^{2} \\
& \leq\left\|(1-a \rho)(x-y)-\rho\left(A^{*}\left(I-J_{\beta}^{B_{2}}\right) A x-A^{*}\left(I-J_{\beta}^{B_{2}}\right) A y\right)\right\|^{2} \\
&=(1-a \rho)^{2}\|x-y\|^{2}-2(1-a \rho) \rho\left(x-y, A^{*}\left(I-J_{\beta}^{B_{2}}\right) A x-A^{*}\left(I-J_{\beta}^{B_{2}}\right) A y\right\rangle \\
& \quad+\rho^{2}\left\|A^{*}\left(I-J_{\beta}^{B_{2}}\right) A x-A^{*}\left(I-J_{\beta}^{B_{2}}\right) A y\right\|^{2} \\
& \leq(1-a \rho)\|x-y\|^{2}-2\left(1-\alpha_{n} \rho\right) \rho \frac{1}{\|A\|^{2}}\left\|A^{*}\left(I-J_{\beta}^{B_{2}}\right) A x-A^{*}\left(I-J_{\beta}^{B_{2}}\right) A y\right\|^{2} \\
&\left.+\rho^{2} \| A^{*}\left(I-J_{\beta}^{B_{2}}\right) A x-A^{*}\left(I-J_{\beta}^{B_{2}}\right) A y\right) \|^{2} .
\end{aligned}
$$

If $\rho \in\left(0,2 /\|A\|^{2}+2\right)$, then $2(1-a \rho) \rho\left(1 /\|A\|^{2}\right) \geq \rho^{2}$. This implies that the conclusion of Lemma 4.1 holds.

Theorem 4.1 Let $H_{1}$ and $H_{2}$ be two real Hilbert spaces, $A: H_{1} \rightarrow H_{2}$ be a linear and bounded operator, and let $A^{*}$ denote the adjoint of $A$. Let $B_{1}: H_{1} \multimap H_{1}$ and $B_{2}: H_{2} \multimap H_{2}$ be two set-valued maximal monotone mappings. Let $\left\{\beta_{n}\right\}$ be a sequence in $(0, \infty),\left\{a_{n}\right\} \subseteq(0,1)$, 
and $\left\{\rho_{n}\right\} \subseteq\left(0,2 /\left(\|A\|^{2}+2\right)\right)$. Let $\Omega$ be the solution set of (SFVIP) and suppose that $\Omega \neq \emptyset$. Let $\left\{x_{n}\right\}$ be defined by

$$
x_{n+1}:=J_{\beta_{n}}^{B_{1}}\left[\left(1-a_{n} \rho_{n}\right) x_{n}-\rho_{n} A^{*}\left(I-J_{\beta_{n}}^{B_{2}}\right) A x_{n}\right]
$$

for each $n \in \mathbb{N}$. Assume that:

$$
\lim _{n \rightarrow \infty} a_{n}=0, \quad \sum_{n=1}^{\infty} a_{n} \rho_{n}=\infty, \quad \liminf _{n \rightarrow \infty} \rho_{n}>0 \quad \text { and } \quad \liminf _{n \rightarrow \infty} \beta_{n}>0 .
$$

Then $\lim _{n \rightarrow \infty} x_{n}=\bar{x}$, where $\bar{x}=P_{\Omega} 0$, i.e., $\bar{x}$ is the minimal norm solution of (SFVIP).

Proof Let $\bar{x}=P_{\Omega} 0$. Take any $w \in \Omega$ and let $w$ be fixed. Then we know that

$$
\begin{aligned}
\left\|x_{n+1}-w\right\| \\
=\left\|J_{\beta_{n}}^{B_{1}}\left[\left(1-a_{n} \rho_{n}\right) x_{n}-\rho_{n} A^{*}\left(I-J_{\beta_{n}}^{B_{2}}\right) A x_{n}\right]-w\right\| \\
=\left\|J_{\beta_{n}}^{B_{1}}\left[\left(1-a_{n} \rho_{n}\right) x_{n}-\rho_{n} A^{*}\left(I-J_{\beta_{n}}^{B_{2}}\right) A x_{n}\right]-J_{\beta_{n}}^{B_{1}}\left[w-\rho_{n} A^{*}\left(I-J_{\beta_{n}}^{B_{2}}\right) A w\right]\right\| \\
\leq\left\|J_{\beta_{n}}^{B_{1}}\left[\left(1-a_{n} \rho_{n}\right) x_{n}-\rho_{n} A^{*}\left(I-J_{\beta_{n}}^{B_{2}}\right) A x_{n}\right]-J_{\beta_{n}}^{B_{1}}\left[\left(1-a_{n} \rho_{n}\right) w-\rho_{n} A^{*}\left(I-J_{\beta_{n}}^{B_{2}}\right) A w\right]\right\| \\
\quad+\left\|J_{\beta_{n}}^{B_{1}}\left[\left(1-a_{n} \rho_{n}\right) w-\rho_{n} A^{*}\left(I-J_{\beta_{n}}^{B_{2}}\right) A w\right]-J_{\beta_{n}}^{B_{1}}\left[w-\rho_{n} A^{*}\left(I-J_{\beta_{n}}^{B_{2}}\right) A w\right]\right\| \\
\leq\left(1-a_{n} \rho_{n}\right)\left\|x_{n}-w\right\|+a_{n} \rho_{n}\|w\|
\end{aligned}
$$

for each $n \in \mathbb{N}$. Then $\left\{x_{n}\right\}$ is a bounded sequence. Further, we have

$$
\begin{aligned}
\left\|x_{n+1}-w\right\|^{2} \\
=\left\|J_{\beta_{n}}^{B_{1}}\left[\left(1-a_{n} \rho_{n}\right) x_{n}-\rho_{n} A^{*}\left(I-J_{\beta_{n}}^{B_{2}}\right) A x_{n}\right]-J_{\beta_{n}}^{B_{1}}\left[w-\rho_{n} A^{*}\left(I-J_{\beta_{n}}^{B_{2}}\right) A w\right]\right\|^{2} \\
\leq\left\|\left[\left(1-a_{n} \rho_{n}\right) x_{n}-\rho_{n} A^{*}\left(I-J_{\beta_{n}}^{B_{2}}\right) A x_{n}\right]-\left[w-\rho_{n} A^{*}\left(I-J_{\beta_{n}}^{B_{2}}\right) A w\right]\right\|^{2} \\
=\left\|\left[x_{n}-\rho_{n} A^{*}\left(I-J_{\beta_{n}}^{B_{2}}\right) A x_{n}\right]-\left[w-\rho_{n} A^{*}\left(I-J_{\beta_{n}}^{B_{2}}\right) A w\right]-a_{n} \rho_{n} x_{n}\right\|^{2} \\
=\left\|\left[x_{n}-\rho_{n} A^{*}\left(I-J_{\beta_{n}}^{B_{2}}\right) A x_{n}\right]-\left[w-\rho_{n} A^{*}\left(I-J_{\beta_{n}}^{B_{2}}\right) A w\right]\right\|^{2} \\
\quad-2 a_{n} \rho_{n}\left\langle\left[x_{n}-\rho_{n} A^{*}\left(I-J_{\beta_{n}}^{B_{2}}\right) A x_{n}\right]-\left[w-\rho_{n} A^{*}\left(I-J_{\beta_{n}}^{B_{2}}\right) A w\right], x_{n}\right\rangle \\
\quad+a_{n} \rho_{n}\left\|x_{n}\right\|^{2}
\end{aligned}
$$

for each $n \in \mathbb{N}$. By (4.1) and Lemma 2.6,

$$
\begin{aligned}
& \left\|x_{n+1}-w\right\|^{2} \\
& \leq\left\|x_{n}-w\right\|^{2}-\left(2 \rho_{n}-\rho_{n}^{2}\|A\|^{2}\right)\left\|\left(I-J_{\beta_{n}}^{B_{2}}\right) A x_{n}-\left(I-J_{\beta_{n}}^{B_{2}}\right) A w\right\|^{2} \\
& \quad-2 a_{n} \rho_{n}\left\langle\left[x_{n}-\rho_{n} A^{*}\left(I-J_{\beta_{n}}^{B_{2}}\right) A x_{n}\right]-\left[w-\rho_{n} A^{*}\left(I-J_{\beta_{n}}^{B_{2}}\right) A w\right], x_{n}\right\rangle \\
& \quad+a_{n} \rho_{n}\left\|x_{n}\right\|^{2} \\
& \leq\left\|x_{n}-w\right\|^{2}-\left(2 \rho_{n}-\rho_{n}^{2}\|A\|^{2}\right)\left\|A x_{n}-J_{\beta_{n}}^{B_{2}} A x_{n}\right\|^{2}+a_{n} \rho_{n}\left\|x_{n}\right\|^{2} \\
& \quad+2 a_{n} \rho_{n}\left\|\left[x_{n}-\rho_{n} A^{*}\left(I-J_{\beta_{n}}^{B_{2}}\right) A x_{n}\right]-\left[w-\rho_{n} A^{*}\left(I-J_{\beta_{n}}^{B_{2}}\right) A w\right]\right\| \cdot\left\|x_{n}\right\|
\end{aligned}
$$


for each $n \in \mathbb{N}$. By (4.1)-(4.2), Lemma 2.4, we know that

$$
\begin{aligned}
& \left\|\left(1-a_{n} \rho_{n}\right) x_{n}-\rho_{n} A^{*}\left(I-J_{\beta_{n}}^{B_{2}}\right) A x_{n}-x_{n+1}\right\|^{2}+\left\|x_{n+1}-w\right\|^{2} \\
& \quad \leq\left\|\left(1-a_{n} \rho_{n}\right) x_{n}-\rho_{n} A^{*}\left(I-J_{\beta_{n}}^{B_{2}}\right) A x_{n}-w\right\|^{2} \\
& \quad=\left\|\left(1-a_{n} \rho_{n}\right) x_{n}-\rho_{n} A^{*}\left(I-J_{\beta_{n}}^{B_{2}}\right) A x_{n}-w+\rho_{n} A^{*}\left(I-J_{\beta_{n}}^{B_{2}}\right) A w\right\|^{2} \\
& \quad \leq\left\|x_{n}-w\right\|^{2}+2 a_{n} \rho_{n}\left\|x_{n}-w\right\| \cdot\left\|x_{n}\right\|+a_{n} \rho_{n}\left\|x_{n}\right\|^{2}
\end{aligned}
$$

for each $n \in \mathbb{N}$. Next, we know that

$$
\begin{gathered}
\left\|\left(1-a_{n} \rho_{n}\right) x_{n}-\rho_{n} A^{*}\left(I-J_{\beta_{n}}^{B_{2}}\right) A x_{n}-x_{n+1}\right\|^{2} \\
=\left\|x_{n}-x_{n+1}\right\|^{2}+\left\|a_{n} \rho_{n} x_{n}+\rho_{n} A^{*}\left(I-J_{\beta_{n}}^{B_{2}}\right) A x_{n}\right\|^{2} \\
\quad-2\left(x_{n}-x_{n+1}, a_{n} \rho_{n} x_{n}+\rho_{n} A^{*}\left(I-J_{\beta_{n}}^{B_{2}}\right) A x_{n}\right\rangle
\end{gathered}
$$

for each $n \in \mathbb{N}$, and

$$
\begin{aligned}
& \left\|x_{n+1}-J_{\beta_{n}}^{B_{1}} x_{n}\right\| \\
& \quad=\left\|J_{\beta_{n}}^{B_{1}}\left[\left(1-a_{n} \rho_{n}\right) x_{n}-\rho_{n} A^{*}\left(I-J_{\beta_{n}}^{B_{2}}\right) A x_{n}\right]-J_{\beta_{n}}^{B_{1}} x_{n}\right\| \\
& \quad \leq\left\|\left[\left(1-a_{n} \rho_{n}\right) x_{n}-\rho_{n} A^{*}\left(I-J_{\beta_{n}}^{B_{2}}\right) A x_{n}\right]-x_{n}\right\| \\
& \quad \leq a_{n} \rho_{n}\left\|x_{n}\right\|+\rho_{n}\left\|A^{*}\left(I-J_{\beta_{n}}^{B_{2}}\right) A x_{n}\right\| \\
& \quad \leq a_{n} \rho_{n}\left\|x_{n}\right\|+\rho_{n}\|A\| \cdot\left\|A x_{n}-J_{\beta_{n}}^{B_{2}} A x_{n}\right\|
\end{aligned}
$$

for each $n \in \mathbb{N}$. Further, we have

$$
\begin{aligned}
&\left\|x_{n+1}-\bar{x}\right\|^{2} \\
&=\left\|J_{\beta_{n}}^{B_{1}}\left[\left(1-a_{n} \rho_{n}\right) x_{n}-\rho_{n} A^{*}\left(I-J_{\beta_{n}}^{B_{2}}\right) A x_{n}\right]-\bar{x}\right\|^{2} \\
& \leq\left\langle\left(1-a_{n} \rho_{n}\right) x_{n}-\rho_{n} A^{*}\left(I-J_{\beta_{n}}^{B_{2}}\right) A x_{n}-\bar{x}+\rho_{n} A^{*}\left(I-J_{\beta_{n}}^{B_{2}}\right) A \bar{x}, x_{n+1}-\bar{x}\right\rangle \\
&=\left\langle\left(1-a_{n} \rho_{n}\right) x_{n}-\rho_{n} A^{*}\left(I-J_{\beta_{n}}^{B_{2}}\right) A x_{n}-\left(1-a_{n} \rho_{n}\right) \bar{x}+\rho_{n} A^{*}\left(I-J_{\beta_{n}}^{B_{2}}\right) A \bar{x}, x_{n+1}-\bar{x}\right\rangle \\
&-a_{n} \rho_{n}\left\langle\bar{x}, x_{n+1}-\bar{x}\right\rangle
\end{aligned}
$$

for each $n \in \mathbb{N}$. Hence,

$$
\begin{aligned}
& \left\|x_{n+1}-\bar{x}\right\|^{2} \\
& \quad \leq \quad\left(1-a_{n} \rho_{n}\right) x_{n}-\rho_{n} A^{*}\left(I-J_{\beta_{n}}^{B_{2}}\right) A x_{n}-\left(1-a_{n} \rho_{n}\right) \bar{x}+\rho_{n} A^{*}\left(I-J_{\beta_{n}}^{B_{2}}\right) A \bar{x}\|\cdot\| x_{n+1}-\bar{x} \| \\
& \quad+a_{n} \rho_{n}\left\langle-\bar{x}, x_{n+1}-\bar{x}\right\rangle \\
& \leq \\
& \leq\left(1-a_{n} \rho_{n}\right)\left\|x_{n}-\bar{x}\right\| \cdot\left\|x_{n+1}-\bar{x}\right\|+a_{n} \rho_{n}\left\langle-\bar{x}, x_{n+1}-\bar{x}\right\rangle
\end{aligned}
$$




$$
\begin{aligned}
& \leq \frac{\left(1-a_{n} \rho_{n}\right)^{2}}{2}\left\|x_{n}-\bar{x}\right\|^{2}+\frac{1}{2}\left\|x_{n+1}-\bar{x}\right\|^{2}+a_{n} \rho_{n}\left\langle-\bar{x}, x_{n+1}-\bar{x}\right\rangle \\
& \leq\left(\frac{1-a_{n} \rho_{n}}{2}\right)\left\|x_{n}-\bar{x}\right\|^{2}+\frac{1}{2}\left\|x_{n+1}-\bar{x}\right\|^{2}+a_{n} \rho_{n}\left\langle-\bar{x}, x_{n+1}-\bar{x}\right\rangle
\end{aligned}
$$

for each $n \in \mathbb{N}$. This implies that

$$
\left\|x_{n+1}-\bar{x}\right\|^{2} \leq\left(1-a_{n} \rho_{n}\right)\left\|x_{n}-\bar{x}\right\|^{2}+2 a_{n} \rho_{n}\left\langle-\bar{x}, x_{n+1}-\bar{x}\right\rangle
$$

for each $n \in \mathbb{N}$.

Case 1: There exists a natural number $N$ such that $\left\|x_{n+1}-\bar{x}\right\| \leq\left\|x_{n}-\bar{x}\right\|$ for each $n \geq N$. So, $\lim _{n \rightarrow \infty}\left\|x_{n}-\bar{x}\right\|$ exists.

Hence, it follows from $\lim _{n \rightarrow \infty}\left\|x_{n}-\bar{x}\right\|$ exists and (4.2) that

$$
\lim _{n \rightarrow \infty}\left(2 \rho_{n}-\rho_{n}^{2}\|A\|^{2}\right)\left\|A x_{n}-J_{\beta_{n}}^{B_{2}} A x_{n}\right\|^{2}=0 .
$$

Clearly,

$$
2 \rho_{n}-\rho_{n}^{2}\|A\|^{2}=\rho_{n}\left(2-\rho_{n}\|A\|^{2}\right) \geq \rho_{n}\left(2-\frac{2\|A\|^{2}}{\|A\|^{2}+2}\right)=\frac{4 \rho_{n}}{\|A\|^{2}+2} .
$$

By assumption, (4.8), and (4.9),

$$
\lim _{n \rightarrow \infty}\left\|A x_{n}-J_{\beta_{n}}^{B_{2}} A x_{n}\right\|=0 .
$$

Without loss of generality, we may assume that $\beta_{n} \geq \beta>0$ for each $n \in \mathbb{N}$. By (4.10) and Lemma 2.4,

$$
\lim _{n \rightarrow \infty}\left\|A x_{n}-J_{\beta}^{B_{2}} A x_{n}\right\|=0 .
$$

By assumption, (4.5), and (4.10),

$$
\lim _{n \rightarrow \infty}\left\|x_{n+1}-J_{\beta_{n}}^{B_{1}} x_{n}\right\|=0
$$

By assumption, $\lim _{n \rightarrow \infty}\left\|x_{n}-\bar{x}\right\|$ exists, $\left\{x_{n}\right\}$ is a bounded sequence, and (4.3), we know that

$$
\lim _{n \rightarrow \infty}\left\|\left(1-a_{n} \rho_{n}\right) x_{n}-\rho_{n} A^{*}\left(I-J_{\beta_{n}}^{B_{2}}\right) A x_{n}-x_{n+1}\right\|=0 .
$$

Clearly,

$$
\left\|a_{n} \rho_{n} x_{n}+\rho_{n} A^{*}\left(I-J_{\beta_{n}}^{B_{2}}\right) A x_{n}\right\| \leq a_{n} \rho_{n}\left\|x_{n}\right\|+\rho_{n}\|A\| \cdot\left\|A x_{n}-J_{\beta_{n}}^{B_{2}} A x_{n}\right\|
$$

for each $n \in \mathbb{N}$. By assumption, (4.10), and (4.14),

$$
\lim _{n \rightarrow \infty}\left\|a_{n} \rho_{n} x_{n}+\rho_{n} A^{*}\left(I-J_{\beta_{n}}^{B_{2}}\right) A x_{n}\right\|=0 .
$$


By (4.15),

$$
\lim _{n \rightarrow \infty}\left\langle x_{n}-x_{n+1}, a_{n} \rho_{n} x_{n}+\rho_{n} A^{*}\left(I-J_{\beta_{n}}^{B_{2}}\right) A x_{n}\right\rangle=0 .
$$

By (4.4), (4.13), (4.15), and (4.16), we know that

$$
\lim _{n \rightarrow \infty}\left\|x_{n+1}-x_{n}\right\|=0 .
$$

By (4.12) and (4.17),

$$
\lim _{n \rightarrow \infty}\left\|x_{n}-J_{\beta_{n}}^{B_{1}} x_{n}\right\|=0
$$

Since $\left\{x_{n}\right\}$ is a bounded sequence, there exists a subsequence $\left\{x_{n_{j}}\right\}$ of $\left\{x_{n}\right\}$ such that $x_{n_{j}} \rightarrow z$ for some $z \in H_{1}$ and

$$
\limsup _{n \rightarrow \infty}\left\langle-\bar{x}, x_{n+1}-\bar{x}\right\rangle=\lim _{n \rightarrow \infty}\left\langle-\bar{x}, x_{n_{j}}-\bar{x}\right\rangle=\langle-\bar{x}, z-\bar{x}\rangle .
$$

Then $A x_{n_{j}} \rightarrow A z \in H_{2}$. By (4.11), (4.18), Lemma 2.2, and Lemma 2.4, we know that $z \in$ $B_{1}^{-1}(0)$ and $A z \in B_{2}^{-1}(0)$. That is, $z \in \Omega$. By Lemma 2.3,

$$
\limsup _{n \rightarrow \infty}\left\langle-\bar{x}, x_{n+1}-\bar{x}\right\rangle=\langle-\bar{x}, z-\bar{x}\rangle \leq 0 .
$$

By (4.7), (4.19), and Lemma 2.8, we know that $\lim _{n \rightarrow \infty} x_{n}=\bar{x}$, where $\bar{x}=P_{\Omega} 0$.

Case 2: Suppose that there exists $\left\{n_{i}\right\}$ of $\{n\}$ such that $\left\|x_{n_{i}}-\bar{x}\right\| \leq\left\|x_{n_{i}+1}-\bar{x}\right\|$ for all $i \in \mathbb{N}$. By Lemma 2.7, there exists a nondecreasing sequence $\left\{m_{k}\right\}$ in $\mathbb{N}$ such that $m_{k} \rightarrow \infty$,

$$
\left\|x_{m_{k}}-\bar{x}\right\| \leq\left\|x_{m_{k}+1}-\bar{x}\right\| \quad \text { and } \quad\left\|x_{k}-\bar{x}\right\| \leq\left\|x_{m_{k}+1}-\bar{x}\right\|
$$

for each $k \in \mathbb{N}$. By (4.2), we have

$$
\begin{aligned}
& \left\|x_{m_{k}+1}-\bar{x}\right\|^{2} \\
& \leq\left\|x_{m_{k}}-\bar{x}\right\|^{2}-\left(2 \rho_{m_{k}}-\rho_{m_{k}}^{2}\|A\|^{2}\right)\left\|A x_{m_{k}}-J_{\beta_{m_{k}}}^{B_{2}} A x_{m_{k}}\right\|^{2} \\
& \quad+a_{m_{k}} \rho_{m_{k}}\left\|x_{m_{k}}\right\|^{2}+2 a_{m_{k}} \rho_{m_{k}}\left\|x_{m_{k}}-\bar{x}\right\| \cdot\left\|x_{m_{k}}\right\|
\end{aligned}
$$

for each $k \in \mathbb{N}$. By (4.20) and (4.21),

$$
\begin{aligned}
& \left(2 \rho_{m_{k}}-\rho_{m_{k}}^{2}\|A\|^{2}\right)\left\|A x_{m_{k}}-J_{\beta_{m_{k}}}^{B_{2}} A x_{m_{k}}\right\|^{2} \\
& \quad \leq\left\|x_{m_{k}}-\bar{x}\right\|^{2}-\left\|x_{m_{k}+1}-\bar{x}\right\|^{2}+a_{m_{k}} \rho_{m_{k}}\left\|x_{m_{k}}\right\|^{2}+2 a_{m_{k}} \rho_{m_{k}}\left\|x_{m_{k}}-\bar{x}\right\| \cdot\left\|x_{m_{k}}\right\| \\
& \leq a_{m_{k}} \rho_{m_{k}}\left\|x_{m_{k}}\right\|^{2}+2 a_{m_{k}} \rho_{m_{k}}\left\|x_{m_{k}}-\bar{x}\right\| \cdot\left\|x_{m_{k}}\right\|
\end{aligned}
$$

for each $k \in \mathbb{N}$. Then following the same argument as the above, we know that

$$
\lim _{k \rightarrow \infty}\left\|A x_{m_{k}}-J_{\beta_{m_{k}}}^{B_{2}} A x_{m_{k}}\right\|=0
$$




$$
\begin{aligned}
& \lim _{k \rightarrow \infty}\left\|A x_{m_{k}}-J_{\beta}^{B_{2}} A x_{m_{k}}\right\|=0, \\
& \lim _{k \rightarrow \infty}\left\|x_{m_{k}+1}-J_{\beta_{m_{k}}}^{B_{1}} A x_{m_{k}}\right\|=0 .
\end{aligned}
$$

By (4.3),

$$
\begin{aligned}
& \left\|\left(1-a_{m_{k}} \rho_{m_{k}}\right) x_{m_{k}}-\rho_{m_{k}} A^{*}\left(I-J_{\beta_{m_{k}}}^{B_{2}}\right) A x_{m_{k}}-x_{m_{k}+1}\right\|^{2} \\
& \quad \leq\left\|x_{m_{k}}-\bar{x}\right\|^{2}-\left\|x_{m_{k}+1}-\bar{x}\right\|^{2}+2 a_{m_{k}} \rho_{m_{k}}\left\|x_{m_{k}}-\bar{x}\right\| \cdot\left\|x_{m_{k}}\right\|+a_{m_{k}} \rho_{m_{k}}\left\|x_{m_{k}}\right\|^{2} \\
& \quad \leq 2 a_{m_{k}} \rho_{m_{k}}\left\|x_{m_{k}}-\bar{x}\right\| \cdot\left\|x_{m_{k}}\right\|+a_{m_{k}} \rho_{m_{k}}\left\|x_{m_{k}}\right\|^{2}
\end{aligned}
$$

for each $k \in \mathbb{N}$. This implies that

$$
\lim _{k \rightarrow \infty}\left\|\left(1-a_{m_{k}} \rho_{m_{k}}\right) x_{m_{k}}-\rho_{m_{k}} A^{*}\left(I-J_{\beta_{m_{k}}}^{B_{2}}\right) A x_{m_{k}}-x_{m_{k}+1}\right\|^{2}=0 .
$$

Following the same argument as the above, we know that

$$
\lim _{k \rightarrow \infty}\left\|x_{m_{k}+1}-x_{m_{k}}\right\|=\lim _{k \rightarrow \infty}\left\|x_{m_{k}}-J_{\beta_{m_{k}}}^{B_{1}} x_{m_{k}}\right\|=0
$$

and

$$
\limsup _{k \rightarrow \infty}\left\langle-\bar{x}, x_{m_{k}+1}-\bar{x}\right\rangle=\langle-\bar{x}, z-\bar{x}\rangle \leq 0
$$

By (4.7) and (4.20),

$$
\begin{aligned}
a_{m_{k}} \rho_{m_{k}}\left\|x_{m_{k}}-\bar{x}\right\|^{2} & \leq\left\|x_{m_{k}}-\bar{x}\right\|^{2}-\left\|x_{m_{k}+1}-\bar{x}\right\|^{2}+2 a_{m_{k}} \rho_{m_{k}}\left\langle-\bar{x}, x_{m_{k}+1}-\bar{x}\right\rangle \\
& \leq 2 a_{m_{k}} \rho_{m_{k}}\left\langle-\bar{x}, x_{m_{k}+1}-\bar{x}\right\rangle
\end{aligned}
$$

for each $k \in \mathbb{N}$. This implies that

$$
\left\|x_{m_{k}}-\bar{x}\right\|^{2} \leq 2\left\langle-\bar{x}, x_{m_{k}+1}-\bar{x}\right\rangle
$$

for each $k \in \mathbb{N}$. By (4.29) and (4.30),

$$
\lim _{k \rightarrow \infty}\left\|x_{m_{k}}-\bar{x}\right\|=0
$$

By (4.28) and (4.31),

$$
\lim _{k \rightarrow \infty}\left\|x_{m_{k}+1}-\bar{x}\right\| \leq \lim _{k \rightarrow \infty}\left\|x_{m_{k}}-x_{m_{k}+1}\right\|+\lim _{k \rightarrow \infty}\left\|x_{m_{k}}-\bar{x}\right\|=0
$$

By (4.20) and (4.32),

$$
\lim _{k \rightarrow \infty}\left\|x_{k}-\bar{x}\right\|=0
$$

Therefore, the proof is completed. 


\section{Applications: (SFOP) and (SFP)}

We get the following results by Theorems 3.1 and 3.2, respectively.

Theorem 5.1 Let $H_{1}$ and $H_{2}$ be two real Hilbert spaces, $A: H_{1} \rightarrow H_{2}$ be a linear and bounded operator, and let $A^{*}$ denote the adjoint of $A$. Let $f: H_{1} \rightarrow \mathbb{R}$ and $g: H_{2} \rightarrow \mathbb{R}$ be two proper lower semicontinuous and convex functions. Let $\left\{a_{n}\right\},\left\{b_{n}\right\},\left\{c_{n}\right\}$, and $\left\{d_{n}\right\}$ be sequences of real numbers in $[0,1]$ with $a_{n}+b_{n}+c_{n}+d_{n}=1$ and $0<a_{n}<1$ for each $n \in \mathbb{N}$. Let $\left\{\beta_{n}\right\}$ be a sequence in $(0, \infty)$. Let $\left\{v_{n}\right\}$ be a bounded sequence in $H$. Let $u \in H$ be fixed. Let $\left\{\rho_{n}\right\} \subseteq\left(0, \frac{2}{\|A\|^{2}+1}\right)$. Let $\Omega$ be the solution set of (SFOP) and suppose that $\Omega \neq \emptyset$. Let $\left\{x_{n}\right\}$ be defined by

$$
\left\{\begin{array}{l}
y_{n}=\arg \min _{z \in H_{2}}\left\{g(z)+\frac{1}{2 \beta_{n}}\left\|z-A x_{n}\right\|^{2}\right\}, \\
z_{n}=x_{n}-\rho_{n} A^{*}\left(A x_{n}-y_{n}\right), \\
w_{n}=\arg \min _{y \in H_{1}}\left\{f(y)+\frac{1}{2 \beta_{n}}\left\|y-z_{n}\right\|^{2}\right\}, \\
x_{n+1}:=a_{n} u+b_{n} x_{n}+c_{n} w_{n}+d_{n} v_{n}, \quad n \in \mathbb{N} .
\end{array}\right.
$$

Assume that:

(i) $\lim _{n \rightarrow \infty} a_{n}=\lim _{n \rightarrow \infty} \frac{d_{n}}{a_{n}}=0 ; \sum_{n=1}^{\infty} a_{n}=\infty ; \sum_{n=1}^{\infty} d_{n}<\infty$;

(ii) $\liminf _{n \rightarrow \infty} c_{n} \rho_{n}>0 ; \liminf _{n \rightarrow \infty} b_{n} c_{n}>0 ; \liminf _{n \rightarrow \infty} \beta_{n}>0$.

Then $\lim _{n \rightarrow \infty} x_{n}=\bar{x}$, where $\bar{x}=P_{\Omega} u$.

Theorem 5.2 Let $H_{1}$ and $H_{2}$ be two real Hilbert spaces, $A: H_{1} \rightarrow H_{2}$ be a linear and bounded operator, and let $A^{*}$ denote the adjoint of $A$. Let $f: H_{1} \rightarrow \mathbb{R}$ and $g: H_{2} \rightarrow \mathbb{R}$ be two proper lower semicontinuous and convex functions. Let $\left\{a_{n}\right\},\left\{b_{n}\right\}$, and $\left\{c_{n}\right\}$ be sequences of real numbers in $[0,1]$ with $a_{n}+b_{n}+c_{n}=1$ and $0<a_{n}<1$ for each $n \in \mathbb{N}$. Let $\left\{\beta_{n}\right\}$ be a sequence in $(0, \infty)$. Let $\left\{v_{n}\right\}$ be a bounded sequence in $H$. Let $u \in H$ be fixed. Let $\left\{\rho_{n}\right\} \subseteq$ $\left(0, \frac{2}{\|A\|^{2}+1}\right)$. Let $\Omega$ be the solution set of (SFOP) and suppose that $\Omega \neq \emptyset$. Let $\left\{x_{n}\right\}$ be defined by

$$
\left\{\begin{array}{l}
y_{n}=\arg \min _{z \in H_{2}}\left\{g(z)+\frac{1}{2 \beta_{n}}\left\|z-A x_{n}\right\|^{2}\right\}, \\
z_{n}=x_{n}-\rho_{n} A^{*}\left(A x_{n}-y_{n}\right), \\
w_{n}=\arg \min _{y \in H_{1}}\left\{f(y)+\frac{1}{2 \beta_{n}}\left\|y-z_{n}\right\|^{2}\right\}, \\
x_{n+1}:=a_{n} u+b_{n} x_{n}+c_{n} w_{n}+v_{n}, \quad n \in \mathbb{N} .
\end{array}\right.
$$

Assume that $\lim _{n \rightarrow \infty} a_{n}=0, \sum_{n=1}^{\infty} a_{n}=\infty, \sum_{n=1}^{\infty}\left\|v_{n}\right\|<\infty, \liminf _{n \rightarrow \infty} c_{n} \rho_{n}>0$, $\liminf _{n \rightarrow \infty} b_{n} c_{n}>0, \liminf _{n \rightarrow \infty} \beta_{n}>0$. Then $\lim _{n \rightarrow \infty} x_{n}=\bar{x}$, where $\bar{x}=P_{\Omega} u$.

By Theorem 4.1, we get the following result.

Theorem 5.3 Let $H_{1}$ and $H_{2}$ be two real Hilbert spaces, $A: H_{1} \rightarrow H_{2}$ be a linear and bounded operator, and let $A^{*}$ denote the adjoint of $A$. Let $f: H_{1} \rightarrow \mathbb{R}$ and $g: H_{2} \rightarrow \mathbb{R}$ be two proper lower semicontinuous and convex functions. Let $\left\{\beta_{n}\right\}$ be a sequence in $(0, \infty)$, $\left\{a_{n}\right\} \subseteq(0,1)$, and $\left\{\rho_{n}\right\} \subseteq\left(0,2 /\left(\|A\|^{2}+2\right)\right)$. Let $\Omega$ be the solution set of (SFOP) and suppose that $\Omega \neq \emptyset$. Let $\left\{x_{n}\right\}$ be defined by

$$
\left\{\begin{array}{l}
y_{n}=\arg \min _{z \in H_{2}}\left\{g(z)+\frac{1}{2 \beta_{n}}\left\|z-A x_{n}\right\|^{2}\right\}, \\
z_{n}=\left(1-a_{n} \rho_{n}\right) x_{n}-\rho_{n} A^{*}\left(A x_{n}-y_{n}\right), \\
x_{n+1}=\arg \min _{y \in H_{1}}\left\{g(y)+\frac{1}{2 \beta_{n}}\left\|y-z_{n}\right\|^{2}\right\}, \quad n \in \mathbb{N} .
\end{array}\right.
$$


Assume that $\lim _{n \rightarrow \infty} a_{n}=0, \sum_{n=1}^{\infty} a_{n} \rho_{n}=\infty, \liminf _{n \rightarrow \infty} \rho_{n}>0$, and $\liminf _{n \rightarrow \infty} \beta_{n}>0$. Then $\lim _{n \rightarrow \infty} x_{n}=\bar{x}$, where $\bar{x}=P_{\Omega} 0$, i.e., $\bar{x}$ is the minimal norm solution of (SFOP).

Let $H$ be a Hilbert space and let $g$ be a proper lower semicontinuous convex function of $H$ into $(-\infty, \infty)$. Then the subdifferential $\partial g$ of $g$ is defined as follows:

$$
\partial g(x)=\{z \in H: g(x)+\langle z, y-x\rangle \leq g(y), \forall y \in H\}
$$

for all $x \in H$. Let $C$ be a nonempty closed convex subset of a real Hilbert space $H$, and $i_{C}$ be the indicator function of $C$, i.e.,

$$
i_{C} x= \begin{cases}0 & \text { if } x \in C, \\ \infty & \text { if } x \notin C\end{cases}
$$

Further, we also define the normal cone $N_{C} u$ of $C$ at $u$ as follows:

$$
N_{C} u=\{z \in H:\langle z, v-u\rangle \leq 0, \forall v \in C\} .
$$

Then $i_{C}$ is a proper lower semicontinuous convex function on $H$, and the subdifferential $\partial i_{C}$ of $i_{C}$ is a maximal monotone operator. So, we can define the resolvent $J_{\lambda}^{\partial i_{C}}$ of $\partial i_{C}$ for $\lambda>0$, i.e.,

$$
J_{\lambda}^{\partial i_{C}} x=\left(I+\lambda \partial i_{C}\right)^{-1} x
$$

for all $x \in H$. By definitions, we know that

$$
\begin{aligned}
\partial i_{C} x & =\left\{z \in H: i_{C} x+\langle z, y-x\rangle \leq i_{C} y, \forall y \in H\right\} \\
& =\{z \in H:\langle z, y-x\rangle \leq 0, \forall y \in C\} \\
& =N_{C} x
\end{aligned}
$$

for all $x \in C$. Hence, for each $\beta>0$, we have that

$$
\begin{aligned}
u=J_{\beta}^{\partial i_{C}} x & \Leftrightarrow x \in u+\beta \partial i_{C} u \quad \Leftrightarrow \quad x-u \in \beta N_{C} u \\
& \Leftrightarrow \quad\langle x-u, y-u\rangle \leq 0, \quad \forall y \in C \\
& \Leftrightarrow u=P_{C} x .
\end{aligned}
$$

Hence, we have the following result by Theorem 3.2.

Theorem 5.4 Let $C$ and $Q$ be two nonempty closed convex subsets of $H_{1}$ and $H_{2}$, respectively. Let $A: H_{1} \rightarrow H_{2}$ be a linear and bounded operator, and let $A^{*}$ denote the adjoint of $A$. Let $\left\{a_{n}\right\},\left\{b_{n}\right\}$, and $\left\{c_{n}\right\}$ be sequences of real numbers in $[0,1]$ with $a_{n}+b_{n}+c_{n}=1$ and $0<a_{n}<1$ for each $n \in \mathbb{N}$. Let $\left\{\beta_{n}\right\}$ be a sequence in $(0, \infty)$. Let $\left\{v_{n}\right\}$ be a bounded sequence in H. Let $u \in H$ be fixed. Let $\left\{\rho_{n}\right\} \subseteq\left(0, \frac{2}{\|A\|^{2}+1}\right)$. Let $\Omega$ be the solution set of (SFP) and suppose that $\Omega \neq \emptyset$. Let $\left\{x_{n}\right\}$ be defined by

$$
x_{n+1}:=a_{n} u+b_{n} x_{n}+c_{n} P_{C}\left[x_{n}-\rho_{n} A^{*}\left(I-P_{Q}\right) A x_{n}\right]+v_{n}
$$


for each $n \in \mathbb{N}$. Assume that $\lim _{n \rightarrow \infty} a_{n}=0, \sum_{n=1}^{\infty} a_{n}=\infty, \liminf _{n \rightarrow \infty} c_{n} \rho_{n}>0$, and $\liminf _{n \rightarrow \infty} b_{n} c_{n}>0$. Then $\lim _{n \rightarrow \infty} x_{n}=\bar{x}$, where $\bar{x}=P_{\Omega} u$.

By Theorem 4.1, we get the following result.

Theorem 5.5 Let $C$ and $Q$ be two nonempty closed convex subsets of $H_{1}$ and $H_{2}$, respectively. Let $A: H_{1} \rightarrow H_{2}$ be a linear and bounded operator, and let $A^{*}$ denote the adjoint of $A$. Let $\left\{\beta_{n}\right\}$ be a sequence in $(0, \infty),\left\{a_{n}\right\} \subseteq(0,1)$, and $\left\{\rho_{n}\right\} \subseteq\left(0,2 /\left(\|A\|^{2}+2\right)\right)$. Let $\Omega$ be the solution set of (SFP) and suppose that $\Omega \neq \emptyset$. Let $\left\{x_{n}\right\}$ be defined by

$$
x_{n+1}:=P_{C}\left[\left(1-a_{n} \rho_{n}\right) x_{n}-\rho_{n} A^{*}\left(I-P_{Q}\right) A x_{n}\right]
$$

for each $n \in \mathbb{N}$. Assume that $\lim _{n \rightarrow \infty} a_{n}=0, \sum_{n=1}^{\infty} a_{n} \rho_{n}=\infty, \liminf _{n \rightarrow \infty} \rho_{n}>0$, and $\liminf _{n \rightarrow \infty} \beta_{n}>0$. Then $\lim _{n \rightarrow \infty} x_{n}=\bar{x}$, where $\bar{x}=P_{\Omega} 0$, i.e., $\bar{x}$ is the minimal norm solution of (SFP).

Remark 5.1 Theorem 5.5 improves some conditions of [13, Theorem 5.5].

\section{Competing interests}

The author declares that they have no competing interests.

\section{Acknowledgements}

The author was supported by the National Science Council of Republic of China. Also, the author is grateful to an anonymous referee for his fruitful comments.

Received: 30 August 2013 Accepted: 1 December 2013 Published: 20 Dec 2013

\section{References}

1. Censor, Y, Elfving, T: A multiprojection algorithm using Bregman projection in a product space. Numer. Algorithms 8 , 221-239 (1994)

2. Byrne, C: Iterative oblique projection onto convex sets and the split feasibility problem. Inverse Probl. 18, 441-453 (2002)

3. Censor, Y, Bortfeld, T, Martin, B, Trofimov, A: A unified approach for inversion problems in intensity modulated radiation therapy. Phys. Med. Biol. 51, 2353-2365 (2003)

4. López, G, Martín-Márquez, V, Xu, HK: Iterative algorithms for the multiple-sets split feasibility problem. In: Censor, Y, Jiang, M, Wang, G (eds.) Biomedical Mathematics: Promising Directions in Imaging, Therapy Planning and Inverse Problems, pp. 243-279. Medical Physics Publishing, Madison (2010)

5. Stark, H: Image Recovery: Theory and Applications. Academic Press, San Diego (1987)

6. Eicke, B: Iteration methods for convexly constrained ill-posed problems in Hilbert space. Numer. Funct. Anal. Optim. 13, 413-429 (1992)

7. Byrne, $\mathrm{C}:$ A unified treatment of some iterative algorithms in signal processing and image reconstruction. Inverse Probl. 20, 103-120 (2004)

8. Dang, Y, Gao, Y: The strong convergence of a KM-CQ-like algorithm for a split feasibility problem. Inverse Probl. 27, 015007 (2011)

9. Masad, E, Reich, S: A note on the multiple-set split convex feasibility problem in Hilbert space. J. Nonlinear Convex Anal. 8, 367-371 (2008)

10. Qu, B, Xiu, N: A note on the CQ algorithm for the split feasibility problem. Inverse Probl. 21, 1655-1665 (2005)

11. Wang, F, Xu, HK: Approximating curve and strong convergence of the CQ algorithm for the split feasibility problem. J. Inequal. Appl. 2010, 102085 (2010)

12. Xu, HK: A variable Krasnosel'skii-Mann algorithm and the multiple-set split feasibility problem. Inverse Probl. 22 2021-2034 (2006)

13. Xu, HK: Iterative methods for the split feasibility problem in infinite-dimensional Hilbert spaces. Inverse Probl. 26, Article ID 105018 (2010)

14. Yang, Q: The relaxed CQ algorithm for solving the split feasibility problem. Inverse Probl. 20, 1261-1266 (2004)

15. Yang, Q: On variable-step relaxed projection algorithm for variational inequalities. J. Math. Anal. Appl. 302, 166-179 (2005)

16. Zhao, J, Yang, Q: Self-adaptive projection methods for the multiple-sets split feasibility problem. Inverse Probl. 27, 035009 (2011)

17. Martinet, B: Régularisation d'inéquations variationnelles par approximations successives. Rev. Fr. Autom. Inform. Rech. Opér. 4, 154-158 (1970)

18. Rockafellar, RT: Monotone operators and the proximal point algorithm. SIAM J. Control Optim. 14, $877-898$ (1976) 
19. Brézis, H, Lions, PL: Produits infinis de résolvantes. Isr. J. Math. 29, 329-345 (1978)

20. Güler, O: On the convergence of the proximal point algorithm for convex minimization. SIAM J. Control Optim. 29, 403-419 (1991)

21. Kamimura, S, Takahashi, W: Approximating solutions of maximal monotone operators in Hilbert spaces. J. Approx. Theory 106, 226-240 (2000)

22. Kamimura, S, Takahashi, W: Strong convergence of a proximal-type algorithm in a Banach space. SIAM J. Optim. 13 938-945 (2002)

23. Nakajo, K, Takahashi, W: Strong convergence theorems for nonexpansive mapping and nonexpansive semigroups. J. Math. Anal. Appl. 279, 372-379 (2003)

24. Solodov, MV, Svaiter, BF: Forcing strong convergence of proximal point iterations in a Hilbert space. Math. Program. 87, 189-202 (2000)

25. Moudafi, A: Split monotone variational inclusions. J. Optim. Theory Appl. 150, 275-283 (2011)

26. Takahashi, W: Introduction to Nonlinear and Convex Analysis. Yokohama Publishers, Yokohama (2009)

27. Osilike, $\mathrm{MO}$, Igbokwe, DI: Weak and strong convergence theorems for fixed points of pseudocontractions and solutions of monotone type operator equations. Comput. Math. Appl. 40, 559-567 (2000)

28. Xu, HK: Iterative algorithm for nonlinear operators. J. Lond. Math. Soc. 2, 240-256 (2002)

29. Browder, FE: Fixed point theorems for noncompact mappings in Hilbert spaces. Proc. Natl. Acad. Sci. USA 53 , 1272-1276 (1965)

30. Takahashi, W: Nonlinear Functional Analysis-Fixed Point Theory and Its Applications. Yokohama Publishers, Yokohama (2000)

31. He, Z, Du, W-S: Nonlinear algorithms approach to split common solution problems. Fixed Point Theory Appl. 2012, 130 (2012)

32. Chuang, CS, Lin, L, Takahashi, W: Halpern's type iterations with perturbations in a Hilbert space: equilibrium solutions and fixed points. J. Glob. Optim. 56, 1591-1601 (2013)

33. Yu, ZT, Lin, LJ, Chuang, CS: A unified study of the split feasible problems with applications. J. Nonlinear Convex Anal. (accepted)

34. Maingé, PE: Strong convergence of projected subgradient methods for nonsmooth and nonstrictly convex minimization. Set-Valued Anal. 16, 899-912 (2008)

35. Aoyama, K, Kimura, Y, Takahashi, W, Toyoda, M: Approximation of common fixed points of a countable family of nonexpansive mappings in a Banach space. Nonlinear Anal. 67, 2350-2360 (2007)

10.1186/1687-1812-2013-350

Cite this article as: Chuang: Strong convergence theorems for the split variational inclusion problem in Hilbert spaces. Fixed Point Theory and Applications 2013, 2013:350

\section{Submit your manuscript to a SpringerOpen ${ }^{\circ}$ journal and benefit from:}

- Convenient online submission

- Rigorous peer review

- Immediate publication on acceptance

Open access: articles freely available online

- High visibility within the field

- Retaining the copyright to your article 